\title{
Ambulatory pulse oximetry monitoring in Japanese COPD outpatients not receiving oxygen therapy
}

Seigo Minami ${ }^{* *}$, Suguru Yamamoto ${ }^{1}$, Yoshitaka Ogata ${ }^{1}$, Takeshi Nakatani ${ }^{2}$, Yoshiko Takeuchi ${ }^{3}$, Masanari Hamaguchi ${ }^{4}$, Taro Koba ${ }^{1}$ and Kiyoshi Komuta ${ }^{1}$

\begin{abstract}
Background: It remains unknown whether desaturation profiles during daily living are associated with prognosis in patients with chronic obstructive pulmonary disease (COPD). Point measurements of resting oxygen saturation by pulse oximetry $\left(\mathrm{SpO}_{2}\right)$ and partial pressure of arterial oxygen $\left(\mathrm{PaO}_{2}\right)$ are not sufficient for assessment of desaturation during activities of daily living. A small number of studies continuously monitored oxygen saturation throughout the day during activities of daily living in stable COPD patients. This study aims to analyse the frequency of desaturation in COPD outpatients, and investigate whether the desaturation profile predicts the risk of exacerbation.

Methods: We studied stable COPD outpatients not receiving supplemental oxygen therapy. Baseline assessments included clinical assessment, respiratory function testing, arterial blood gas analysis, body mass index, and the COPD Assessment Test (CAT). Patients underwent 24-hour ambulatory monitoring of $\mathrm{SpO}_{2}$ during activities of daily living. Exacerbations of COPD and death from any cause were recorded.

Results: Fifty-one patients were enrolled in the study, including 12 current smokers who were excluded from the analyses in case high serum carboxyhaemoglobin concentrations resulted in inaccurately high $\mathrm{SpO}_{2}$ readings. The mean percent predicted forced expiratory volume in one second ( $\% \mathrm{FEV}_{1}$ ) was $50.9 \%$. The mean proportion of $\mathrm{SpO}_{2}$ values below $90 \%$ was $3.0 \%$ during the day and $7.4 \%$ during the night. There were no daytime desaturators, defined as $\geq 30 \%$ of daytime $\mathrm{SpO}_{2}$ values below $90 \%$. Twenty-one exacerbations occurred in 13 patients during the mean follow-up period of 26.4 months. Univariate and multivariate Cox proportional hazards analyses did not detect any significant factors associated with exacerbation.
\end{abstract}

Conclusions: Our 24-hour ambulatory oximetry monitoring provided precise data regarding the desaturation profiles of COPD outpatients. Both daytime and nighttime desaturations were infrequent. The proportion of ambulatory $\mathrm{SpO}_{2}$ values below $90 \%$ was not a significant predictor of exacerbation.

Keywords: Activities of daily living, Chronic obstructive pulmonary disease (COPD), Desaturator, Exacerbation, Outpatients, Pulse oximetry

\footnotetext{
* Correspondence: seigominami@oph.gr.jp

'Department of Respiratory Medicine, Osaka Police Hospital,

10-31 Kitayama-cho, Tennoji-ku, Osaka 543-0035, Japan

Full list of author information is available at the end of the article
} 


\section{Background}

Chronic obstructive pulmonary disease (COPD) is a leading cause of morbidity and disability worldwide, and is predicted to become the third highest cause of death by 2020 [1]. Desaturation profiles during a 6-minute walk test (6MWT) may predict prognosis primarily in patients with severe COPD with a percent predicted forced expiratory volume in one second $\left(\mathrm{FEV}_{1}\right)$ of $<50 \%$ [2]. Time to desaturation during a $6 \mathrm{MWT}$ also predicts desaturation time in 24-hour ambulatory oximetry monitoring primarily in moderately hypoxaemic COPD patients with a resting partial pressure of arterial oxygen $\left(\mathrm{PaO}_{2}\right)$ between 60 and $70 \mathrm{mmHg}$ [3]. However, it remains unknown whether desaturation profiles measured by ambulatory oximetry can predict prognosis in COPD patients. Transient desaturations have been observed in patients with moderate to severe chronic pulmonary disorders, even without significant resting hypoxemia [4]. Point measurements of resting oxygen saturation by pulse oximetry $\left(\mathrm{SpO}_{2}\right)$ and $\mathrm{PaO}_{2}$, the conventional parameters used to determine requirements of long-term oxygen therapy, are not sufficient for assessment of desaturation during activities of daily living [5]. Field walking tests such as the 6MWT, which is the standard test used for assessment of functional exercise tolerance, do not always provide a good reflection of variations in oxygen saturation, because most activities of daily living are performed at submaximal levels of effort. 6MWT results did not predict the degree of desaturation during defecation in patients with chronic respiratory failure [6]. Conventional assessment methods are therefore not satisfactory for obtaining a comprehensive understanding of oxygen saturation throughout the day.

Pulse oximetry is a rapid, non-invasive method of monitoring the oxygen saturation of haemoglobin. Recent technological advances have enabled development of lowcost, small, user-friendly, portable pulse oximeters that can record data for over 24 hours. Many studies have evaluated the usefulness of pulse oximetry in COPD patients, but most studies only monitored patients continuously during the night or for a short period during the day. Although several studies monitored patients continuously during the day, most of these included patients with severe COPD on long-term oxygen therapy, or exclusively analysed patients on long-term oxygen therapy.

This study aimed to evaluate the desaturation profiles of Japanese COPD outpatients not receiving supplemental oxygen therapy during activities of daily living at home using continuous 24-hour pulse oximetry monitoring, and analyse the frequency of desaturation and relationships between the desaturation profile and the clinical characteristics and risk of exacerbation. The ability of the desaturation profile to predict exacerbation of COPD was investigated.

\section{Methods}

\section{Patient selection}

Patients were recruited from the outpatient clinic in the Department of Respiratory Medicine at Osaka Police Hospital. The inclusion criteria were: (1) clinically stable COPD according to the Global Initiative on Obstructive Lung Disease guidelines, with a $\mathrm{FEV}_{1}$ to forced vital capacity ratio of $<70 \%$ and minimal or no reversibility to $\beta_{2}$-agonists $(<200 \mathrm{~mL}$ and/or $<15 \%)$; (2) able to walk independently or with a cane; and (3) sufficient cognitive function to follow the instructions for using the pulse oximeter. Patients were excluded if they were currently hospitalised, if they had experienced an exacerbation requiring hospitalisation or administration of antibiotics or steroids during the preceding 3 months, if they had other significant respiratory diseases or medical problems that precluded ambulatory activities at home, and if they were receiving supplemental oxygen therapy.

\section{Experimental design}

Within 1 month of ambulatory oximetry monitoring, all patients underwent spirometry, arterial blood gas analysis, assessment of the modified Medical Research Council (mMRC) dyspnoea scale score, and the Japanese version of the COPD assessment test (CAT) (GlaxoSmithKline; http://www.catestonline.org/) [7,8]. Spirometry was performed using an autospirometer (Autospirometer System 7; Minato Medical Science, Osaka, Japan) according to the American Thoracic Society guidelines. Samples for arterial blood gas analysis were obtained from the radial artery with the patient resting in the sitting position and breathing room air, and $\mathrm{PaO}_{2}$ and partial pressure of arterial carbon dioxide $\left(\mathrm{PaCO}_{2}\right)$ were immediately measured using a blood gas analyser (RAPIDPoint 405 Arterial Blood Gas Analyzer; Siemens Healthcare Diagnostics Inc., Tarrytown, NY, USA).

A portable pulse oximeter (PULSOX-Me300; KonicaMinolta, Tokyo, Japan) was used to obtain continuous oximetry data over a 24-hour period. $\mathrm{SpO}_{2}$ and the pulserate waveform were recorded every second. A nurse individually instructed each patient on the proper use of the portable oximeter before the start of monitoring. The finger probe of the portable oximeter was positioned on the patient's non-dominant hand to minimise interference during normal daily activities. The portable oximeter was attached to the patient's wrist during the monitoring period. Periods during which the heart rate fell abruptly by $\geq 25$ beats/minute were excluded from the analyses. All data were downloaded to a computer for analysis (DS-Me version 2.10). A calibration check according to the manufacturer's instructions was performed before and after use. Patients were instructed to keep an activity log to record the times of major daily activities (sleeping, eating, walking outdoors, bathing, and other physical activities). Based on 
the patient's activity log, periods of sleep were defined as night, and all other periods were defined as day. Patients were encouraged to perform all normal daily ambulatory activities, and to maintain their baseline levels of activity. The daytime and nighttime mean $\mathrm{SpO}_{2}$ value, proportion of $\mathrm{SpO}_{2}$ values below $90 \%$, and heart rate were analysed. The $3 \%$ oxygen desaturation index (3\%ODI) during the night was measured to detect patients with possible obstructive sleep apnoea (OSA) [9].

Patients were followed up for as long as possible after their ambulatory oximetry monitoring, and exacerbations and survival were analysed. Exacerbations were recorded from the day of oximetry monitoring. Follow-up ended on 30 November 2013. Exacerbation was defined as an increase in respiratory symptoms lasting at least 3 days and requiring treatment with antibiotics or systemic steroids.

The primary outcome was the proportion of desaturators, defined by Levi-Valensi et al. as patients with $\geq 30 \%$ of $\mathrm{SpO}_{2}$ values below 90\% [10]. This definition was validated by Casanova et al. [11] and has also been used in other recent studies of 24-hour or daytime oximetry monitoring $[3,5,12]$. The secondary outcomes were the mean $\mathrm{SpO}_{2}$, heart rate and occurrence of exacerbation. Based on the results of previous studies [3,11], the proportion of desaturators was estimated to be approximately 24\% in COPD patients with a resting $\mathrm{PaO}_{2}$ of 60-70 $\mathrm{mmHg}$. The proportion of desaturators in this study was estimated to be $8 \%$, because we expected the study to include a higher proportion of patients with mild COPD than previous studies. For a one-sided alpha of $5 \%$ and a power of $80 \%$, we estimated that 47 evaluable subjects would be needed. Given the possibility of incomplete data in some patients, we considered that 50 subjects would be needed for this study. The study was approved by the Osaka Police Hospital ethics committee. All patients provided written informed consent for inclusion in the study.

\section{Data analysis}

The values for normally distributed continuous variables, discrete variables, and categorical variables are expressed as the mean \pm standard deviation (SD), median (range), and frequency, respectively. Comparisons between groups were performed using the unpaired $t$-test for normally distributed continuous variables. Simple and multiple regression analyses were performed to evaluate relationships between variables and the proportion of daytime $\mathrm{SpO}_{2}$ values below $90 \%$. The following factors were included in the simple regression analyses: percent predicted $\mathrm{FEV}_{1}$ (\% FEV ${ }_{1}$ ), mMRC dyspnoea grade, CAT score, resting $\mathrm{PaO}_{2}$, resting $\mathrm{PaCO}_{2}$, body mass index (BMI), and age. All variables with a $p$ value of $<0.2$ on univariate analysis were included in the multiple regression analysis. The multiple
Table 1 Baseline characteristics of ex-/non-smokers (n= 39)

\begin{tabular}{|c|c|c|}
\hline Age (years) & Mean \pm SD & $71.6 \pm 8.8$ \\
\hline Sex & Male/female & $36 / 3$ \\
\hline Smoking pack/years & Mean \pm SD & $68.2 \pm 33.4$ \\
\hline BMI $\left(\mathrm{kg} / \mathrm{m}^{2}\right)$ & Mean \pm SD & $23.1 \pm 3.8$ \\
\hline Underweight $\left(\mathrm{BMl}<18.5 \mathrm{~kg} / \mathrm{m}^{2}\right)$ & n (\%) & $4(10.3)$ \\
\hline Overweight (BMI 25-30 kg/m²) & n (\%) & $5(12.8)$ \\
\hline Obese $\left(\mathrm{BMI} \geq 30 \mathrm{~kg} / \mathrm{m}^{2}\right)$ & n (\%) & $2(5.1)$ \\
\hline $\begin{array}{l}\text { Unadjusted Charlson Comorbidity } \\
\text { Index }\end{array}$ & Median (range) & $1(0-4)$ \\
\hline $\begin{array}{l}\text { Age-adjusted Charlson Comorbidity } \\
\text { Index }\end{array}$ & Median (range) & $5(2-9)$ \\
\hline \multicolumn{3}{|l|}{ Treatment } \\
\hline Long-acting muscarinic antagonist & n (\%) & $26(67 \%)$ \\
\hline Long-acting $\beta_{2}$ agonist & n (\%) & $27(69 \%)$ \\
\hline Inhaled corticosteroid & n (\%) & $27(69 \%)$ \\
\hline $\mathrm{PaO}_{2}(\mathrm{mmHg})$ & Mean \pm SD & $78.2 \pm 8.9$ \\
\hline $\mathrm{PaCO}_{2}(\mathrm{mmHg})$ & Mean \pm SD & $39.1 \pm 4.9$ \\
\hline GOLD stage & I/II/III/IV & 2/18/13/6 \\
\hline $\mathrm{FEV}_{1}(\mathrm{~L})$ & Mean \pm SD & $1.3 \pm 0.6$ \\
\hline $\mathrm{FEV}_{1}$ (\%predicted) & Mean \pm SD & $50.9 \pm 18.5$ \\
\hline $\mathrm{FVC}(\mathrm{L})$ & Mean \pm SD & $2.3 \pm 1.0$ \\
\hline \multirow[t]{2}{*}{ mMRC dyspnoea grade } & Mean \pm SD & $2.2 \pm 1.1$ \\
\hline & Median (range) & $2(0-4)$ \\
\hline \multirow[t]{2}{*}{ CAT score } & Mean \pm SD & $11.7 \pm 7.0$ \\
\hline & Median (range) & $10(0-29)$ \\
\hline
\end{tabular}

BMI, Body mass index; CAT, Chronic obstructive pulmonary disease assessment test; $F_{1 V}$, Forced expiratory volume in one second; FVC, Forced vital capacity; GOLD, Global Initiative on Obstructive Lung Disease; mMRC, Modified Medical Research Council; SD, Standard deviation.

Table 2 Pulse oximetry monitoring results in ex-/non-smokers $(n=39)$

\begin{tabular}{lll}
\hline & Daytime & Nighttime \\
\hline Monitoring duration (hours) & & \\
$\quad$ Mean $\pm \mathrm{SD}$ & $14.5 \pm 3.7$ & $8.5 \pm 3.0$ \\
Proportion of $\mathrm{SpO}_{2}$ values $<90 \%(\%)$ & & \\
$\quad$ Mean $\pm \mathrm{SD}$ & $3.0 \pm 5.5$ & $7.4 \pm 16.1$ \\
$\quad$ Median (range) & $1.1(0.0-28.1)$ & $1.3(0.0-87.3)$ \\
Mean SpO & $(\%)$ & \\
$\quad$ Mean $\pm \mathrm{SD}$ & & $93.7 \pm 1.8$ \\
$\quad$ Median (range) & $94.7 \pm 1.2$ & \\
Heart rate (beats/min) & $94.9(90.7-97.4)$ & $93.9(88.8-96.8)$ \\
$\quad$ Mean $\pm \mathrm{SD}$ & & $69.0 \pm 9.0$ \\
Median (range) & $76.9 \pm 10.6$ & $68.2(49.4-87.1)$ \\
\hline
\end{tabular}

$\mathrm{SD}$, Standard deviation; $\mathrm{SpO}_{2}$, Oxygen saturation by pulse oximetry. 
Table 3 Characteristics of exacerbations in ex-/non-smokers $(\boldsymbol{n}=39)$

\begin{tabular}{lll}
\hline $\begin{array}{l}\text { Follow-up duration } \\
\text { (months) }\end{array}$ & Mean \pm SD & $26.4 \pm 6.7$ \\
All exacerbations & Median (range) & 27.8 (4.1-32.8) \\
$\quad \begin{array}{l}\text { Exacerbation-related } \\
\text { admission }\end{array}$ & Total admissions/patients & $13 / 9$ \\
\multicolumn{1}{c}{ Antibiotic use } & Total uses/patients & $15 / 10$ \\
\multicolumn{1}{c}{ Systemic steroid use } & Total uses/patients & $4 / 4$ \\
\hline
\end{tabular}

$\mathrm{SD}$, Standard deviation.

regression analysis results are expressed as the unstandardized regression coefficient ( $\beta$ ) with the corresponding 95\% confidence interval, and the coefficient of determination $\left(\mathrm{R}^{2}\right)$. Univariate and multivariate Cox proportional hazards models were used to evaluate relationships between the variables and exacerbation. The following factors were included in the multivariate analysis: ageadjusted Charlson Comorbidity Index [13], BMI, \%FEV ${ }_{1}$, and proportion of $\mathrm{SpO}_{2}$ values below $90 \%$ during the day and night. The Cox proportional hazards analysis results are expressed as risk ratio (RR) with the $95 \%$ confidence interval. A two-tailed $p$ value of $<0.05$ was considered statistically significant. Statistical analyses were performed using StatMate statistical software (StatMate version IV; ATMS Co., Ltd., Tokyo, Japan). The sample calculation was performed using EZR (Saitama Medical Centre, Jichi Medical University, Saitama City, Japan), a graphical user interface for R (The R Foundation for Statistical Computing) [14]. EZR is a modified version of $R$ commander designed to add statistical functions and frequently used in biostatistics.

\section{Results}

A total of 51 Japanese patients were enrolled in the study from February 2011 to September 2011. Thirty-eight patients were ex-smokers, 12 were current smokers, and 1 was a non-smoker who had been chronically exposed to excessive environmental tobacco smoke. We excluded the 12 current smokers from our analyses, because smoking status was not considered at study entry and some current smokers were unexpectedly included. Current smoking may increase $\mathrm{SpO}_{2}$ values due to a high serum carboxyhaemoglobin $(\mathrm{COHb})$ concentration [15-17]. The characteristics of the ex-/non-smokers are shown in Table 1.

The daytime and nighttime oximetry monitoring results are shown in Table 2. There were no daytime desaturators and three nighttime desaturators. Although we did not confirm OSA by polysomnography, the results showed possible OSA (3\%ODI of more than 15 desaturations/hour) in six patients [9]. Comparison of these 6 patients with the remaining 33 patients found no significant differences in the proportion of $\mathrm{SpO}_{2}$ values below $90 \%$ in the daytime $(1.7 \pm 2.1$ vs $3.2 \pm 6.0 \%, p=0.28)$ or nighttime $(15.4 \pm 9.9$ vs $5.9 \pm 17.0 \%, p=0.08)$ or in the mean daytime $\mathrm{SpO}_{2}$ value ( $94.6 \pm 0.8$ vs $94.7 \pm 1.3 \%, p=0.86$ ), but did find a significant difference in the mean nighttime $\mathrm{SpO}_{2}$ value $(92.3 \pm 0.9$ vs $93.9 \pm 1.8 \%, p=0.03)$. In the nine patients with a resting $\mathrm{PaO}_{2}$ of $60-70 \mathrm{mmHg}$ (resting $\mathrm{PaO}_{2} 66.2 \pm$ $2.8 \mathrm{mmHg}$ ), including no daytime and two nighttime desaturators, the proportion of $\mathrm{SpO}_{2}$ values below $90 \%$ was $8.4 \pm 9.0 \%$ during the day and $20.2 \pm 28.5 \%$ during the night, and the 3\%ODI was more than 15 desaturations/ hour in one ex-smoker (15.6 desaturations/hour).

Simple regression analysis showed that higher $\% \mathrm{FEV}_{1}$ $(\beta=-0.12, p=0.01)$, higher $\mathrm{PaO}_{2}(\beta=-0.30, p=0.002)$ and lower mMRC dyspnoea grade $(\beta=2.38, p=0.002)$

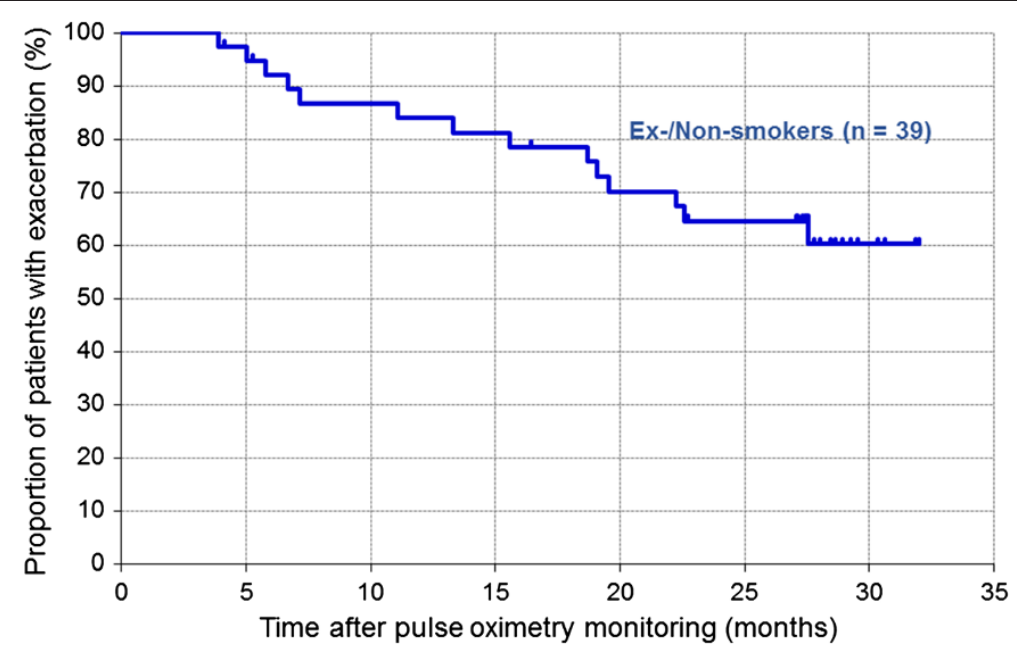

Figure 1 Kaplan-Meier curves for exacerbation of COPD in 39 ex-/non-smokers (blue line). 
were significantly associated with a lower proportion of daytime $\mathrm{SpO}_{2}$ values below 90\% (Additional file 1: Data 1). Multivariate analysis identified only $\mathrm{PaO}_{2}$ as a significant predictor of the proportion of daytime $\mathrm{SpO}_{2}$ values below 90\% ( $\beta=-0.21, p=0.04)$ (Additional file 1: Data 2).

Five ex-smokers were lost to follow-up. Two exsmokers died of acute heart failure and unknown cause, respectively. Thirty-two ex-/non-smokers were alive and still followed up at the time of data cut-off. One third of the patients experienced exacerbations during the followup period (Table 3). The median time from oximetry monitoring to the first exacerbation was not reached (Figure 1). Univariate (Table 4) and multivariate (Table 5) analyses did not detect any factors that were significantly associated with exacerbation.

\section{Discussion}

This study of Japanese COPD outpatients not receiving supplemental oxygen therapy included no daytime desaturators and few nighttime desaturators. The proportions of daytime and nighttime $\mathrm{SpO}_{2}$ values below $90 \%$ did not predict exacerbation.

Table 4 Univariate Cox proportional hazards analysis of relationships between variables and exacerbation in ex-/non-smokers $(n=39)$

\begin{tabular}{|c|c|c|c|}
\hline Variable & Risk ratio & $95 \% \mathrm{Cl}$ & $p$ \\
\hline Age (years) & 1.04 & $0.97-1.10$ & 0.26 \\
\hline $\begin{array}{l}\text { Unadjusted Charlson Comorbidity } \\
\text { Index }\end{array}$ & 0.93 & $0.57-1.51$ & 0.76 \\
\hline $\begin{array}{l}\text { Age-adjusted Charlson Comorbidity } \\
\text { Index }\end{array}$ & 1.06 & $0.76-1.46$ & 0.74 \\
\hline Pack/years & 1.00 & $0.98-1.01$ & 0.69 \\
\hline Body mass index & 0.87 & $0.73-1.03$ & 0.10 \\
\hline mMRC dyspnoea grade & 1.19 & $0.73-1.96$ & 0.49 \\
\hline CAT score & 1.08 & $1.00-1.16$ & 0.054 \\
\hline $\mathrm{PaO}_{2}$ & 0.97 & $0.92-1.03$ & 0.35 \\
\hline $\mathrm{PaCO}_{2}$ & 0.95 & $0.84-1.08$ & 0.45 \\
\hline $\mathrm{FEV}_{1}$ & 0.60 & $0.23-1.53$ & 0.28 \\
\hline$\% \mathrm{FEV}_{1}$ & 0.99 & $0.96-1.02$ & 0.45 \\
\hline \multicolumn{4}{|l|}{ Daytime } \\
\hline Proportion of $\mathrm{SpO}_{2}$ values < $90 \%(\%)$ & 1.01 & $0.92-1.11$ & 0.78 \\
\hline Mean heart rate & 1.02 & $0.97-1.07$ & 0.42 \\
\hline \multicolumn{4}{|l|}{ Nighttime } \\
\hline Proportion of $\mathrm{SpO}_{2}$ values $<90 \%$ & 0.98 & $0.92-1.03$ & 0.41 \\
\hline $3 \% O D I$ & 0.92 & $0.82-1.02$ & 0.12 \\
\hline Mean heart rate & 1.01 & $0.95-1.07$ & 0.71 \\
\hline
\end{tabular}

CAT, Chronic obstructive pulmonary disease assessment test; $\mathrm{Cl}$, Confidence interval; FEV $_{1}$, Forced expiratory volume in one second; mMRC, Modified Medical Research Council; ODI, Oxygen desaturation index; $\mathrm{PaCO}_{2}$, Partial pressure of arterial carbon dioxide; $\mathrm{PaO}_{2}$, Partial pressure of arterial oxygen; $\mathrm{SpO}_{2}$, Oxygen saturation by pulse oximetry.
Table 5 Multivariate Cox proportional hazards analysis of relationships between variables and exacerbation in ex-/non-smokers $(n=39)$

\begin{tabular}{llll}
\hline Variable & Risk ratio & $\mathbf{9 5 \%} \mathrm{Cl}$ & $\boldsymbol{p}$ \\
\hline $\begin{array}{l}\text { Age-adjusted Charlson Comorbidity } \\
\text { Index }\end{array}$ & 0.96 & $0.67-1.37$ & 0.82 \\
Body mass index & 0.88 & $0.72-1.06$ & 0.18 \\
CAT score & 1.08 & $0.99-1.18$ & 0.10 \\
$\% \mathrm{FEV}_{1}$ & 0.99 & $0.95-1.02$ & 0.45 \\
$\begin{array}{l}\text { Daytime proportion of } \mathrm{SpO}_{2} \\
\text { values < } 90 \%\end{array}$ & 1.00 & $0.84-1.18$ & 0.97 \\
Nighttime proportion of $\mathrm{SpO}_{2}$ & 0.99 & $0.92-1.05$ & 0.68
\end{tabular}
values $<90 \%$

CAT, Chronic obstructive pulmonary disease assessment test; $\mathrm{Cl}$, confidence interval; $\mathrm{FEV}_{1}$, forced expiratory volume in one second; $\mathrm{SpO}_{2}$, Oxygen saturation by pulse oximetry.

To the best of our knowledge, only four previous studies have reported the results of continuous 24-hour oxygen saturation monitoring during activities of daily living using a portable pulse oximeter (Table 6) $[3,5,11,18]$. The population of the present study differed from the populations of these previous studies in terms of race, disease severity $\left(\% \mathrm{FEV}_{1}\right.$ and resting $\left.\mathrm{PaO}_{2}\right)$, physique (BMI), and $\mathrm{SpO}_{2}$ values. Patients with more severe COPD generally tend to be more underweight [19-21]. However, the patients in this study had milder COPD but were more underweight than patients in previous non-Asian studies. Additionally, our oximetry results were much better than in previous studies. Patients in this study had less frequent daytime and nighttime desaturations than those in the previous studies. Although even the nine patients with a resting $\mathrm{PaO}_{2}$ of $60-70 \mathrm{mmHg}$ had better oxygen saturation profiles than patients in the previous non-Asian studies, their desaturation profiles and pulmonary function were comparable to those of the 55 non-desaturators in the study by Casanova et al., which also found that non-desaturators were less hypercapnic and less hypoxemic during the daytime than desaturators in spite of having similar pulmonary function and Saint George's Respiratory Questionnaire scores [11]. Our nine patients with a resting $\mathrm{PaO}_{2}$ of $60-70 \mathrm{mmHg}$ had lower resting $\mathrm{PaCO}_{2}$ values than patients in the previous studies. These comparisons suggest that desaturators are likely to have hypercapnic respiratory failure.

In this study, oximetry results did not predict exacerbation. This is consistent with the findings of Trauer et al., who reported that ambulatory oximetry results in patients with a resting $\mathrm{PaO}_{2}$ of $56-70 \mathrm{mmHg}$ did not predict exacerbation or survival [12]. They proposed four reasons for the lack of association between oximetry results and survival: 1) oximetry results are not fundamentally important for predicting prognosis, 2) progression of COPD is unpredictably heterogeneous, 3) the sample size was not 
Table 6 Studies of continuous 24-hour oximetry monitoring during activities of daily living

\begin{tabular}{|c|c|c|c|c|c|c|c|c|}
\hline $\begin{array}{l}\text { Authors } \\
\text { (Year) } \\
\text { [Ref] }\end{array}$ & $\mathrm{N}$ & $\begin{array}{l}\mathrm{PaO}_{2} \\
\text { inclusion } \\
\text { criteria }\end{array}$ & $\begin{array}{l}\text { Supplemental } \\
\text { oxygen } \\
\text { therapy }\end{array}$ & $\begin{array}{l}\mathrm{PaO}_{2} \\
\mathrm{PaCO}_{2} \\
(\mathrm{mmHg})\end{array}$ & $\% \mathrm{FEV}_{1}$ & BMI & $\begin{array}{l}\text { Proportion of } \\
\text { desaturators }\end{array}$ & $\begin{array}{l}\text { Mean proportion } \\
\text { of } \mathrm{SpO}_{2} \text { values } \\
<90 \%\end{array}$ \\
\hline \multirow{3}{*}{$\begin{array}{l}\text { Soguel Schenkel } \\
\text { (1996) [18] }\end{array}$} & \multirow[t]{3}{*}{30 inpts } & \multirow[t]{3}{*}{ Not defined } & \multirow[t]{3}{*}{3 Patients* } & Median (range) & Median (range) & Median (range) & \multirow[t]{3}{*}{ Not described } & \multirow[t]{3}{*}{ Not described } \\
\hline & & & & $68(54-89)$ & $37(16-64)$ & $25.5(17.1-42.5)$ & & \\
\hline & & & & $42(35-51)$ & & & & \\
\hline \multirow{8}{*}{$\begin{array}{l}\text { Casanova } \\
(2006)[11]\end{array}$} & \multirow[t]{8}{*}{88 outpts } & \multirow[t]{8}{*}{$60-70 \mathrm{mmHg}$} & \multirow[t]{8}{*}{ None } & Mean \pm SD & Mean \pm SD & Mean \pm SD & Daytime 22\% & Non-desaturators \\
\hline & & & & $64.7 \pm 2.8$ & $38 \pm 13$ & $27 \pm 4$ & Nighttime 50\% & 24 -hour 12.2\% \\
\hline & & & & $45 \pm 5.7$ & & & & Daytime 8.9\% \\
\hline & & & & & & & & Nighttime 18.8\% \\
\hline & & & & & & & & Desaturators \\
\hline & & & & & & & & 24-hour 55.1\% \\
\hline & & & & & & & & Daytime 42.3\% \\
\hline & & & & & & & & Nighttime $77.3 \%$ \\
\hline \multirow{3}{*}{$\begin{array}{l}\text { Garcia-Talavera } \\
\text { (2008) [3] }\end{array}$} & \multirow[t]{3}{*}{67 outpts } & \multirow[t]{3}{*}{$60-70 \mathrm{mmHg}$} & \multirow[t]{3}{*}{ None } & Median (range) & Median (range) & \multirow[t]{3}{*}{ Not described } & 24-hour 30\% & 24-hour 17\% \\
\hline & & & & $66(60-70)$ & $37(16-64)$ & & Daytime 25\% & Daytime 15\% \\
\hline & & & & $45(32-57)$ & & & Nighttime 45\% & Nighttime 23\% \\
\hline \multirow[t]{3}{*}{ Trauer (2012) [5] } & \multirow[t]{3}{*}{35 outpts } & \multirow[t]{3}{*}{$56-70 \mathrm{mmHg}$} & \multirow[t]{3}{*}{ None } & Mean \pm SD & Mean \pm SD & Mean \pm SD & 24-hour 54\% & 24-hour 41.9\% \\
\hline & & & & $64.1 \pm 4.5$ & $37.5 \pm 13.2$ & $27.1 \pm 7.0$ & Daytime 40\% & Daytime $30.9 \%$ \\
\hline & & & & $44.2 \pm 6.0$ & & & Nighttime 77\% & Nighttime $60.6 \%$ \\
\hline \multirow[t]{5}{*}{ This study } & \multirow[t]{3}{*}{39 outpts } & \multirow[t]{3}{*}{ Not defined } & \multirow[t]{3}{*}{ None } & Mean \pm SD & Mean \pm SD & Mean \pm SD & Daytime 0\% & Daytime 3.0\% \\
\hline & & & & $78.2 \pm 8.9$ & $50.9 \pm 18.5$ & $23.1 \pm 3.8$ & Nighttime 8\% & Nighttime $7.4 \%$ \\
\hline & & & & $39.1 \pm 4.9$ & & & & \\
\hline & \multirow[t]{2}{*}{9 outpts** } & \multirow[t]{2}{*}{$60-70 \mathrm{mmHg}$} & \multirow[t]{2}{*}{ None } & $66.2 \pm 3.0$ & $37.0 \pm 14.6$ & $23.9 \pm 4.8$ & Daytime 0\% & Daytime 8.4\% \\
\hline & & & & $38.0 \pm 5.4$ & & & Nighttime 22\% & Nighttime $20.2 \%$ \\
\hline
\end{tabular}

*Three patients had not previously received supplemental oxygen therapy, but started nocturnal oxygen therapy during admission to a pulmonary rehabilitation programme.

**Nine patients in this study had more severe COPD with mild-to-moderate hypoxaemia $\left(\mathrm{PaO}_{2} 60-70 \mathrm{mmHg}\right)$.

$\mathrm{BMI}$, body mass index; $\mathrm{FEV}_{1}$, Forced expiratory volume in one second; Inpts, inpatients; Outpts, outpatients; PaO ${ }_{2}$, partial pressure of arterial oxygen; Ref, Reference; $\mathrm{SD}$, Standard deviation; $\mathrm{SpO}_{2}$, Oxygen saturation by pulse oximetry.

large enough to detect differences, and 4) low ambulatory oxygen saturation reflected greater levels of physical activity. In the present study, the lack of association between oximetry results and the risk of exacerbation may be related to the small sample size, as the patients had mild COPD and therefore had lower rates of exacerbation and death than in the study by Trauer et al. [12]. However, the CAT score may be an independent predictor of exacerbation, as also recently reported in other studies [22,23].

This study has some limitations. First, despite using an activity log, it was not possible to accurately determine the patients' physical activities at specific times. It is difficult for patients to accurately record activities by the minute, or accurately recall activities over longer periods of time [24]. Most patients in this study had inaccurate recordings, and patients frequently forgot to record any activities at all. The resulting activity logs were not useful for comparison with pulse oximetry results. It has been reported that patients with COPD are markedly inactive in daily life [25], and that the reduction in physical activity starts in the early stages of the disease, even before COPD is diagnosed [26]. It is therefore possible that the minimal desaturations recorded in this study reflected reduced activity levels. Use of motion sensors such as accelerometers seems to be a promising alternative to patient-reported activity logs. Only one previous study reported concomitant measurement of $\mathrm{SpO}_{2}$ and physical activity by oximeter, accelerometry and actigraphy, respectively [27]. However, the analysis in this study divided activities into only four categories: walking, slow-intermittent-walking, active-notwalking, and resting. These broad classifications are not sufficient for linking desaturation profiles with activities of daily living. Second, the influence of $\mathrm{COHb}$ on $\mathrm{SpO}_{2}$ values in the 12 current smokers was not assessed, because the $\mathrm{COHb}$ concentrations were not measured. Therefore, we excluded the current smokers from our analyses, and it remains unknown whether ambulatory oximetry monitoring is reliable in smokers. Finally, 
oximetry monitoring was performed only once, as in the previous studies. Only the study by Casanova et al. reported repeat 24-hour oximetry monitoring, at 1-3 weeks after the initial monitoring in 11 patients [11]. They did not find significant differences between the results of the two monitoring periods. Although it is necessary to investigate whether a single 24-hour monitoring period is sufficient for evaluation of the desaturation profile, it is difficult to perform monitoring over multiple periods because of patient discomfort and disturbance of activities of daily living while the monitor is attached.

\section{Conclusions}

Our 24-hour ambulatory oximetry monitoring provided precise data regarding the desaturation profiles of Japanese outpatients with COPD. Both daytime and nighttime desaturations were infrequent. The proportion of $\mathrm{SpO}_{2}$ values below $90 \%$ did not predict exacerbation of COPD.

\section{Availability of supporting data}

The data sets supporting the results of this article are included within the article and its additional files.

\section{Additional files}

Additional file 1: Data 1. Simple regression analysis of relationships between variables and the proportion of daytime $\mathrm{SpO}_{2}$ values below $90 \%$ (ex-/non-smokers, $n=39$ ). Data 2 . Multiple regression analysis of relationships between variables and the proportion of daytime $\mathrm{SpO}_{2}$ values below $90 \%$ (ex-/non-smokers, $\mathrm{n}=39$ ).

\section{Competing interests}

The authors declare that they have no competing interests.

\section{Authors' contributions}

SM analysed the data and drafted the manuscript. SY designed the study. All authors contributed to conducting the study and collecting the data, and read and approved the final manuscript.

\section{Acknowledgements}

We thank Mayumi Nakayama, Yoko Munemori, Chikayo Tarumi, and Miki Yamaoka at Osaka Police Hospital for carefully instructing the patients; Yoshinori Yamada at Teijin Pharma Limited and Yoshitomo Kawanishi at Teijin Home Healthcare Limited for technical advice and support; and all the subjects for their participation.

\section{Author details}

'Department of Respiratory Medicine, Osaka Police Hospital, 10-31 Kitayama-cho, Tennoji-ku, Osaka 543-0035, Japan. ²Department of Internal Medicine, National Hospital Organization Kinki-Chuo Chest Medical Center, 1180 Nagasone-cho, Kita-ku, Sakai, Osaka 591-8555, Japan.

${ }^{3}$ Department of Respiratory Medicine, Allergy and Rheumatic Diseases, Osaka University Graduate School of Medicine, 2-2 Yamada-oka, Suita, Osaka 565-0871, Japan. ${ }^{4}$ Osaka Prefectural Medical Center for Respiratory and Allergic Diseases, 3-7-1 Habikino, Osaka 583-8588, Japan.

Received: 18 January 2014 Accepted: 5 April 2014

Published: 17 April 2014

\section{References}

1. Murray CJ, Lopez AD: Alternative projections of mortality and disability by cause 1990-2020: Global Burden of Disease Study. Lancet 1997, 349(9064):1498-1504.

2. Casanova C, Cote C, Marin JM, Pinto-Plata V, De Torres JP, Aguirre-Jaime A, Vassaux C, Celli BR: Distance and oxygen desaturation during the 6-min walk test as predictors of long-term mortality in patients with COPD. Chest 2008, 134(4):746-752.

3. Garcia-Talavera I, Garcia CH, Macario CC, De Torres JP, Celli BR, AguirreJaime A: Time to desaturation in the 6-min walking distance test predicts 24-hour oximetry in COPD patients with a PO2 between 60 and $70 \mathrm{mmHg}$. Respir Med 2008, 102(7):1026-1032.

4. Sliwinski P, Lagosz M, Gorecka D, Zielinski J: The adequacy of oxygenation in COPD patients undergoing long-term oxygen therapy assessed by pulse oximetry at home. Eur Respir J 1994, 7(2):274-278.

5. Trauer JM, Gielen C, Trauer T, Steinfort CL: Inability of single resting arterial blood gas to predict significant hypoxaemia in COPD. Intern Med J 2012.

6. Delmastro M, Santoro C, Nava S: Respiratory changes during defecation in patients with chronic respiratory failure. Eur Respir J 2004, 23(4):617-619

7. Jones PW, Brusselle G, Dal Negro RW, Ferrer M, Kardos P, Levy ML, Perez T, Soler Cataluna JJ, van der Molen T, Adamek L, Banik N: Properties of the COPD assessment test in a cross-sectional European study. Eur Respir J 2011, 38(1):29-35.

8. Jones PW, Harding G, Berry P, Wiklund I, Chen WH, Kline Leidy N: Development and first validation of the COPD Assessment Test. Eur Respir J 2009, 34(3):648-654.

9. Nigro CA, Aimaretti S, Gonzalez S, Rhodius E: Validation of the WristOx 3100 oximeter for the diagnosis of sleep apnea/hypopnea syndrome. Sleep Breath 2009, 13(2):127-136.

10. Levi-Valensi $P$, Aubry $P$, Rida Z: Nocturnal hypoxemia and long-term oxygen therapy in COPD patients with daytime $\mathrm{PaO} 260-70 \mathrm{mmHg}$. Lung 1990, 168(Suppl):770-775

11. Casanova C, Hernandez MC, Sanchez A, Garcia-Talavera I, De Torres JP, Abreu J, Valencia JM, Aguirre-Jaime A, Celli BR: Twenty-four-hour ambulatory oximetry monitoring in COPD patients with moderate hypoxemia. Respir Care 2006, 51(12):1416-1423.

12. Trauer JM, Gielen CA, Aminazad A, Steinfort CL: Ambulatory oximetry fails to predict survival in chronic obstructive pulmonary disease with mild-to-moderate hypoxaemia. Respirology 2013, 18(2):377-382.

13. Charlson M, Szatrowski TP, Peterson J, Gold J: Validation of a combined comorbidity index. J Clin Epidemiol 1994, 47(11):1245-1251.

14. Kanda Y: Investigation of the freely available easy-to-use software 'EZR' for medical statistics. Bone Marrow Transplant 2013, 48(3):452-458.

15. Bozeman WP, Myers RA, Barish RA: Confirmation of the pulse oximetry gap in carbon monoxide poisoning. Ann Emerg Med 1997, 30(5):608-611.

16. Buckley RG, Aks SE, Eshom JL, Rydman R, Schaider J, Shayne P: The pulse oximetry gap in carbon monoxide intoxication. Ann Emerg Med 1994, 24(2):252-255

17. Hampson NB: Pulse oximetry in severe carbon monoxide poisoning. Chest 1998, 114(4):1036-1041.

18. Soguel Schenkel N, Burdet L, De Muralt B, Fitting JW: Oxygen saturation during daily activities in chronic obstructive pulmonary disease. Eur Respir J 1996, 9(12):2584-2589.

19. Engelen MP, Schols AM, Baken WC, Wesseling GJ, Wouters EF: Nutritional depletion in relation to respiratory and peripheral skeletal muscle function in out-patients with COPD. Eur Respir J 1994, 7(10):1793-1797.

20. Schols AM, Soeters PB, Dingemans AM, Mostert R, Frantzen PJ, Wouters EF: Prevalence and characteristics of nutritional depletion in patients with stable COPD eligible for pulmonary rehabilitation. Am Rev Respir Dis 1993, 147(5):1151-1156.

21. Wilson DO, Rogers RM, Wright EC, Anthonisen NR: Body weight in chronic obstructive pulmonary disease. The National Institutes of Health Intermittent Positive-Pressure Breathing Trial. Am Rev Respir Dis 1989, 139(6):1435-1438.

22. Varol Y, Ozacar R, Balci G, Usta L, Taymaz Z: Assessing the Effectiveness of the COPD Assessment Test (CAT) to Evaluate COPD Severity and Exacerbation Rates. COPD 2014, 11(2):221-225.

23. Zhao YF, Jiang YP, Zhou LF, Wu XL: Prognostic Value of Chronic Obstructive Pulmonary Disease Assessment Test, Serum Copeptin, Procalcitonin and C-reactive Protein: Six Months of Outcome in Patients 
With Acute Exacerbation of Chronic Obstructive Pulmonary Disease. Am J Med Sci 2013 [Epub ahead of print].

24. Pitta F, Troosters T, Probst VS, Spruit MA, Decramer M, Gosselink R:

Quantifying physical activity in daily life with questionnaires and motion sensors in COPD. Eur Respir J 2006, 27(5):1040-1055.

25. Pitta F, Troosters T, Spruit MA, Probst VS, Decramer M, Gosselink R. Characteristics of physical activities in daily life in chronic obstructive pulmonary disease. Am J Respir Crit Care Med 2005, 171(9):972-977.

26. Van Remoortel H, Hornikx M, Demeyer H, Langer D, Burtin C, Decramer M, Gosselink R, Janssens W, Troosters T: Daily physical activity in subjects with newly diagnosed COPD. Thorax 2013, 68(10):962-963.

27. Cutaia M, Brehm R, Cohen M: The relationship of the BODE index to oxygen saturation during daily activities in patients with chronic obstructive pulmonary disease. Lung 2011, 189(4):269-277.

doi:10.1186/2049-6958-9-24

Cite this article as: Minami et al:: Ambulatory pulse oximetry monitoring in Japanese COPD outpatients not receiving oxygen therapy.

Multidisciplinary Respiratory Medicine 2014 9:24.

\section{Submit your next manuscript to BioMed Central and take full advantage of:}

- Convenient online submission

- Thorough peer review

- No space constraints or color figure charges

- Immediate publication on acceptance

- Inclusion in PubMed, CAS, Scopus and Google Scholar

- Research which is freely available for redistribution 